\title{
Clinical Reasoning: A 62-year-old man with history of catheter ablation presenting with recurrent strokes
}

Valerie Jeanneret, MD, Ryan B. Peterson, MD, and Carlos S. Kase, MD

Neurology ${ }^{\circledR}$ 2020;95:e3065-e3069. doi:10.1212/WNL.0000000000010606
Correspondence

Dr. Jeanneret

vjeanne@emory.edu

\section{Section 1}

A 62-year-old man presented with a syncopal episode followed by left hemiparesis. Symptoms started right after landing from a 2-hour flight. The week prior to presentation he had general malaise, nausea, vomiting, and poor appetite. He was diagnosed with pneumonia and completed a course of cefdinir. His medical history was relevant for paroxysmal atrial fibrillation (AF), for which he underwent catheter ablation 1 month prior to presentation, when he was on apixaban, started 2 weeks prior to the procedure, and continued until the presentation to our hospital.

Upon initial assessment in the emergency department, the patient was well-appearing, febrile to $39.8^{\circ} \mathrm{C}$, with regular heart rate of 126 beats per minute. He had no facial weakness; there was left leg weakness with $1 / 5$ strength and $3 / 5$ arm strength bilaterally. Reflexes were brisk in both lower extremities, with plantar reflexes extensor on the left, flexor on the right. Cranial nerve, sensory, and cerebellar examinations revealed no abnormalities. Shortly after, his examination significantly improved, with only minimal residual weakness in the left leg.

Initial CT of the head, perfusion imaging, and CT angiogram (CTA) of the head and neck were normal. The patient was not a candidate for thrombolytics because he had taken apixaban the morning of presentation.

\section{Questions for consideration:}

1. Where do you localize the symptoms?

2. What are the differential diagnoses?

GO TO SECTION 2

From the Departments of Neurology (V.J., C.S.K.) and Radiology and Imaging Sciences (R.B.P.), Emory University School of Medicine, Atlanta, GA.

Go to Neurology.org/N for full disclosures. Funding information and disclosures deemed relevant by the authors, if any, are provided at the end of the article. 


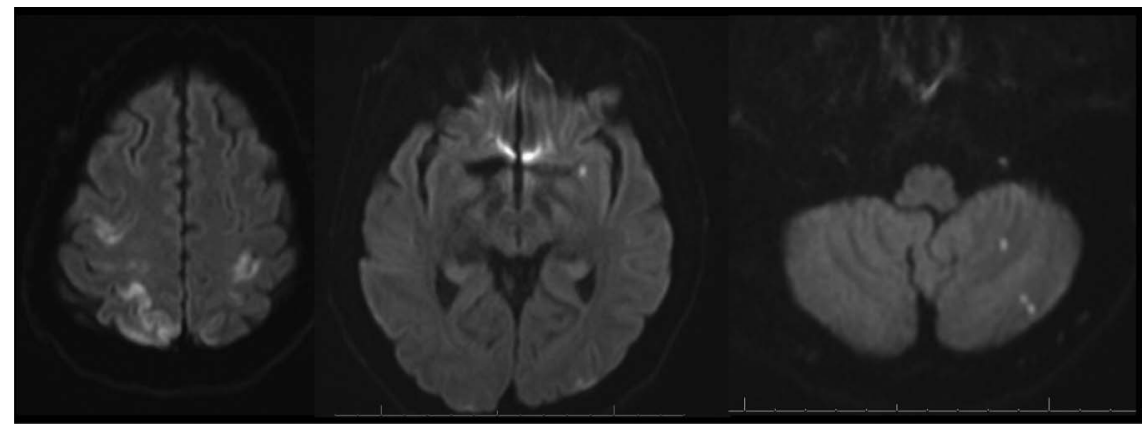

Axial MRI diffusion-weighted images demonstrate multiple areas of punctate and gyriform cortical restricted diffusion (apparent diffusion coefficient correlation not shown) consistent with acute infarcts throughout multiple vascular territories. There was no susceptibility artifact on susceptibility-weighted sequences (not shown).

\section{Section 2}

Cervical spine pathology was considered given the bilateral upper extremity and left leg weakness, without facial involvement. A single cerebrovascular lesion would not explain the patient's deficits; therefore bilateral cortical or subcortical lesions would be an alternative consideration.

The differential at this point was broad. Given the acute onset of focal neurologic symptoms and the history of AF, the primary concern was for acute stroke. Because the examination findings were suggestive of multiple vascular territories affected, multifocal strokes were likely. Cardioembolism was highly suspected, given the history of AF; ascending aortic atherosclerotic plaque and septic emboli were considered as well.

Because of fever and tachycardia, bacterial or viral meningoencephalitis was in the differential diagnosis, and in the setting of multifocal neurologic symptoms, brain abscesses and septic emboli were considered. A lumbar puncture was not performed because the patient had taken apixaban on the day of presentation. He was started empirically on broad-spectrum antibiotics including ceftriaxone, vancomycin, and ampicillin, and was admitted to the intensive care unit.

Epidural abscess was a concern as well in view of fever, bilateral upper extremity weakness, and upper motor neuron findings on examination. Traumatic spinal cord injury secondary to the fall was considered less likely given that hyporeflexia and flaccid paresis would be expected.
MRI of the cervical spine revealed multilevel degenerative changes of the spine with no cord signal changes. Brain MRI showed multiple punctuate areas of acute infarction in the left cerebellar hemisphere, left basal ganglia, and multiple regions of gyriform restricted diffusion in the cerebral cortex bilaterally (figure 1).

Given fever and embolic phenomena, the concern for infective endocarditis was high. A transthoracic echocardiogram showed no evidence of vegetations or intracardiac thrombus, the ejection fraction was normal, no wall motion abnormalities were detected, and a mildly dilated left atrium was documented $\left(35-41 \mathrm{~mL} / \mathrm{m}^{2}\right)$. Blood cultures drawn on admission were negative. At that time, it was thought that oral anticoagulation had failed to prevent cardioembolism and the patient was started on intravenous heparin drip.

Three days after presentation, the patient became unresponsive. He was found to be in $\mathrm{AF}$ with rapid ventricular response with heart rate up to 180 beats per minute, and persistently febrile with maximal temperature of $40.4^{\circ} \mathrm{C}$. On neurologic examination, he was somnolent and disoriented, and had left arm weakness and minimal movement of both lower extremities.

\section{Question for consideration:}

1. What additional diagnostic testing can further clarify the underlying etiology? 

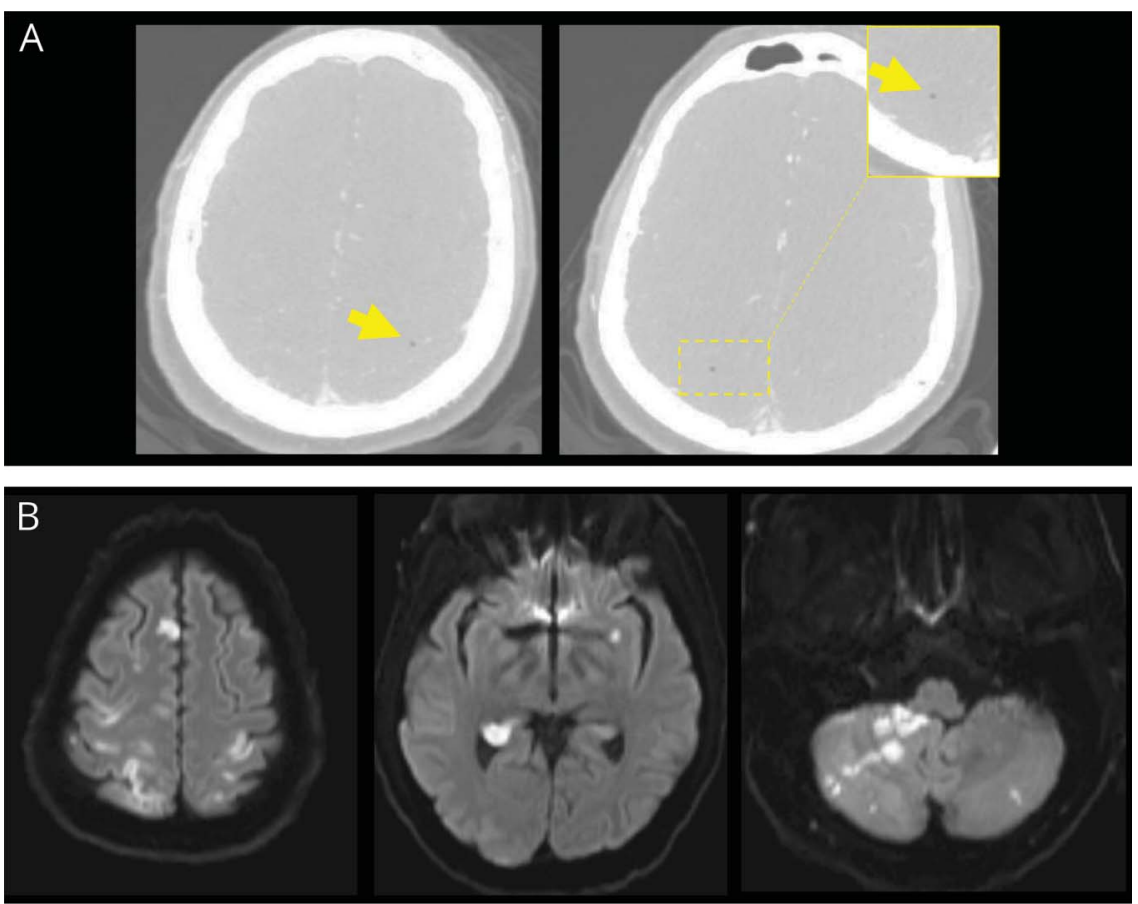

(A) Axial CT angiogram of the head on lung windows demonstrates small hypoattenuating foci in the peripheral brain parenchyma compatible with intravascular air in the parietal lobes bilaterally (arrow). (B) Axial MRI diffusion-weighted images demonstrate multiple new and larger acute infarctions in the right cerebellar hemisphere, right hippocampus, left basal ganglia, and bilateral cerebral cortex.

\section{Section 3}

A repeat head CT and CTA was immediately obtained and showed new punctuate hypoattenuating foci in the peripheral parenchyma at the vertex supportive of air emboli (figure 2A). Follow-up brain MRI showed multiple new areas of acute infarction (figure 2B). No areas of susceptibility artifact were seen on susceptibility-weighted sequences that would suggest presence of either blood products or intravascular air. Due to persistent fevers, repeat blood cultures were obtained, which grew Streptococcus anginosus. CT chest showed several small foci of air adjacent to the thoracic esophagus and posterior to the left atrium (figure 3 ), which was suggestive of an atrioesophageal fistula (AEF).

\section{Questions for consideration:}

1. Which teams should be involved?

2. What treatment is indicated?

\section{GO TO SECTION 4}


Figure 3 CT chest

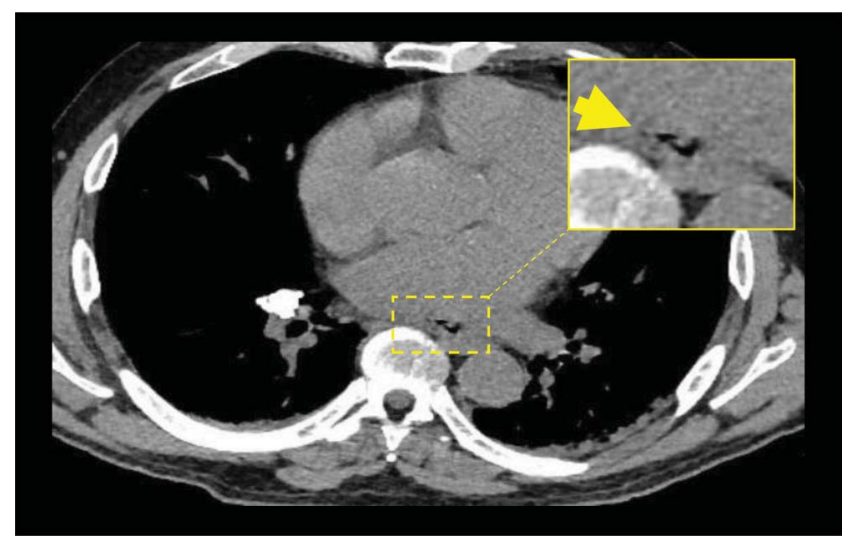

Axial noncontrast CT chest demonstrates air tracking from the right aspect of the esophageal air column into the retropharyngeal space next to the left atrium (arrow).

\section{Section 4}

The cardiothoracic surgery team was consulted, and the AEF was repaired surgically via right thoracotomy. The patient tolerated the operation without incident, but in the postoperative course he was found to have a splenic abscess that required drainage. He was discharged to an acute rehabilitation facility 1 month after his initial presentation with minimal neurologic deficits.

\section{Discussion}

Catheter ablation has become a common nonpharmacologic approach for the management of AF. AEF is a rare complication, with an incidence of less than $0.1 \%$, and typically occurs $2-4$ weeks after the ablation. ${ }^{1-3}$

Patients can present with fever, fatigue, nausea, vomiting, chest pain, dysphagia, odynophagia, and gastrointestinal bleeding. Neurologic manifestations are the second most common presenting symptom, ${ }^{3}$ and these include focal neurologic deficits, seizures, confusion, and loss of consciousness. ${ }^{3,4}$

The fistula formation is thought to be due to thermal injury of anterior esophageal arteries causing ischemia and ulceration of the esophageal mucosa. The fistula creates a one-way valve, allowing esophageal contents into the left atrium due to the transiently increased intraesophageal pressure associated with swallowing. ${ }^{5}$

Risk factors for procedural AEF include chronic AF (as these patients usually have large atrial size), use of general anesthesia, shorter distance between the left atrium and the esophagus, extensive ablation on the posterior wall of the left atrium, and gastroesophageal reflux. ${ }^{1,2}$ Although there is no strong evidence to support this, the use of esophageal temperature monitoring protocols, esophageal cooling, displacement of the esophagus during the procedure, and proton pump inhibitor use have been suggested to prevent esophageal injuries and avoid development of an AEF. ${ }^{3}$

It is important to have a high index of suspicion for AEF in patients presenting with embolic stroke after an ablation. ${ }^{6}$ A transthoracic echocardiogram may demonstrate air in the left side of the heart or pericardium; however, the test of choice is a CT of the chest with contrast to look for pneumomediastinum or pneumopericardium. Transesophageal echocardiogram is contraindicated in suspected AEF due to risk for further esophageal damage and potential for air embolization during esophageal insufflation. $1,3,7$

Air emboli are easily missed on routine neuroimaging for multiple reasons. First, the small foci of air can be skipped on conventional 2.5 and $5 \mathrm{~mm}$ slice thickness commonly used for noncontrast head CTs. In this case, the CTA identified the findings because of the $0.625 \mathrm{~mm}$ slice thickness. Second, air is better identified using a "lung window" (width $\sim 1,500$, level $\sim-660$ ), which is not routinely performed on neuroimaging. Air emboli can appear as signal intensity loss in gradient echo and susceptibilityweighted images. Of note, small foci of intravascular air can infarct brain parenchyma and then be reabsorbed rapidly by the time of imaging.

The mortality of AEF is high, with reported rates between $67 \%$ and $100 \%{ }^{1,3}$ Surgical repair of the fistula, including repair of the atrial and esophageal tears via thoracotomy, is the favored treatment. Esophageal stenting and conservative management have been reported but are less favored. ${ }^{8}$

\section{Study funding}

No targeted funding reported.

\section{Disclosure}

The authors report no disclosures relevant to the manuscript. Go to Neurology.org/N for full disclosures.

Appendix Authors

\begin{tabular}{lll}
\hline Name & Location & Contribution \\
\hline $\begin{array}{l}\text { Valerie } \\
\text { Jeanneret, } \\
\text { MD }\end{array}$ & $\begin{array}{l}\text { Department of Neurology, Emory } \\
\text { University, Atlanta, GA }\end{array}$ & $\begin{array}{l}\text { Literature review } \\
\text { and manuscript } \\
\text { drafting }\end{array}$ \\
\hline $\begin{array}{l}\text { Ryan B. } \\
\text { Peterson, } \\
\text { MD }\end{array}$ & $\begin{array}{l}\text { Department of Radiology and } \\
\text { Imaging Sciences, Emory University, }\end{array}$ & $\begin{array}{l}\text { Literature and } \\
\text { manuscript review }\end{array}$ \\
\hline $\begin{array}{l}\text { Carlos S. } \\
\text { Kase, MD }\end{array}$ & Department of Neurology, Emory & $\begin{array}{l}\text { Literature and } \\
\text { manuscript review }\end{array}$ \\
\hline
\end{tabular}




\section{References}

1. Nair KK, Danon A, Valaparambil A, Koruth JS, Singh SM. Atrioesophageal fistula: a review. J Atr Fibrillation 2015;8:1331.

2. Nair KK, Shurrab M, Skanes A, et al. The prevalence and risk factors for atrioesophageal fistula after percutaneous radiofrequency catheter ablation for atrial fibrillation: the Canadian experience. J Interv Card Electrophysiol 2014;39:139-144.

3. Han HC, Ha FJ, Sanders P, et al. Atrioesophageal fistula: clinical presentation, procedural characteristics, diagnostic investigations, and treatment outcomes. Circ Arrhythm Electrophysiol 2017;10:e005579.

4. Stollberger C, Pulgram T, Finsterer J. Neurological consequences of atrioesophageal fistula after radiofrequency ablation in atrial fibrillation. Arch Neurol 2009;66:884-887.
5. Kapur S, Barbhaiya C, Deneke T, Michaud GF. Esophageal injury and atrioesophageal fistula caused by ablation for atrial fibrillation. Circulation 2017;136: 1247-1255.

6. Zima LA, Fornoff LE, Surdell DL. Atrioesophageal fistula: considerations for the neurological clinician. Clin Neurol Neurosurg 2018;170:58-60.

7. Yarlagadda B, Deneke T, Turagam M, et al. Temporal relationships between esophageal injury type and progression in patients undergoing atrial fibrillation catheter ablation. Heart Rhythm 2019;16:204-212.

8. Yousuf T, Keshmiri H, Bulwa Z, et al. Management of atrio-esophageal fistula following left atrial ablation. Cardiol Res 2016;7:36-45. 


\section{Neurology}

\section{Clinical Reasoning: A 62-year-old man with history of catheter ablation presenting with recurrent strokes}

Valerie Jeanneret, Ryan B. Peterson and Carlos S. Kase

Neurology 2020;95;e3065-e3069 Published Online before print August 6, 2020

DOI 10.1212/WNL.0000000000010606

This information is current as of August 6, 2020

\section{Updated Information \&} Services

References

Subspecialty Collections

\section{Permissions \& Licensing}

Reprints including high resolution figures, can be found at: http://n.neurology.org/content/95/22/e3065.full

This article cites 8 articles, 2 of which you can access for free at: http://n.neurology.org/content/95/22/e3065.full\#ref-list-1

This article, along with others on similar topics, appears in the following collection(s):

\section{All Cerebrovascular disease/Stroke}

http://n.neurology.org/cgi/collection/all_cerebrovascular_disease_strok e

\section{Cardiac}

http://n.neurology.org/cgi/collection/cardiac

Cardiac; see Cerebrovascular Disease/Cardiac

http://n.neurology.org/cgi/collection/cardiac_see_cerebrovascular_dise ase-cardiac

Embolism

http://n.neurology.org/cgi/collection/embolism

Information about reproducing this article in parts (figures,tables) or in its entirety can be found online at:

http://www.neurology.org/about/about_the_journal\#permissions

Information about ordering reprints can be found online: http://n.neurology.org/subscribers/advertise

Neurology ${ }^{\circledR}$ is the official journal of the American Academy of Neurology. Published continuously since 1951, it is now a weekly with 48 issues per year. Copyright @ 2020 American Academy of Neurology. All rights reserved. Print ISSN: 0028-3878. Online ISSN: 1526-632X.

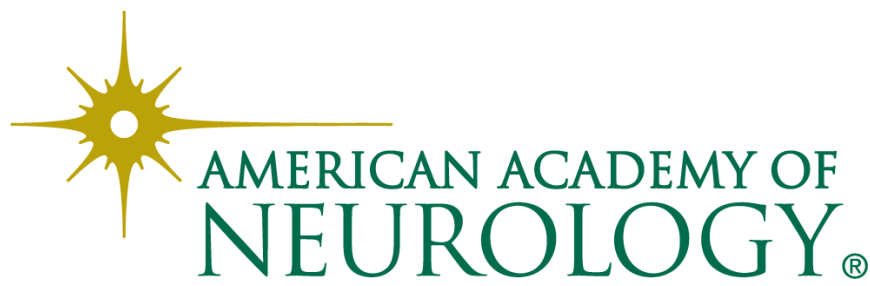

